\title{
A versatile, immobilized gold catalyst for the reductive amination of aldehydes in batch and flow
}

\author{
Adela I. Carrillo, ${ }^{a}$ Patricia Llanes ${ }^{a}$ and Miquel A. Pericàs ${ }^{a, b, *}$ \\ An efficient and environmentally friendly catalytic route for the reductive amination of carbonyl compounds has been designed. First, a one-pot procedure \\ has been followed for the synthesis and incorporation of gold nanoparticles (AuNPs) into a mesoporous silica solid by using light as an abundant and clean \\ energy source. Then, the as-prepared material has been successfully employed as an heterogeneous catalyst in the production of secondary and tertiary \\ amines by reductive amination using $\mathrm{Ph}(\mathrm{Me})_{2} \mathrm{SiH}$ as the reducing agent. The endurance of the catalyst has been demonstrated in batch, and a continuous \\ flow process allowing the safe preparation of multigram amounts of reductive amination products (accumulated TON $=434$ in $18 \mathrm{~h}$ operation involving 6 \\ sequential examples) has been implemented. The scope of the reaction has also been extended to the synthesis of more challenging active pharmaceutical \\ ingredients (APIs), such as indoprofen precursors and biomass-derived products, which were obtained in good to excellent yields.
}

\section{Introduction}

Due to the ubiquity of amines among natural products, and the prevalence of amino groups in the molecules of synthetic intermediates, pharmaceutical ingredients and fine chemicals, the efficient, economical and environmentally friendly synthesis ${ }^{1}$ of amines is nowadays a very active field in preparative organic chemistry. ${ }^{1}$ Strategies involving $\mathrm{C}-\mathrm{N}$ bond formation are generally used to introduce the desired amine functionalities into organic compounds. ${ }^{2}$ Although various methods are known, ${ }^{3}$ the broad availability and low cost of starting materials such as aldehydes, ketones and amines make the direct reductive amination of carbonyl compounds one of the most practical and efficient approaches to the preparation of complex amines. From a practical perspective, one-pot processes allowing the initial imine formation in the presence of the reducing agent are the subject of current interest. ${ }^{4}$ In this context, silanes containing $\mathrm{Si}-\mathrm{H}$ bonds have appeared as a competitive, green alternative for the production of fine chemicals through mild and selective reduction processes. ${ }^{4 c, 5}$ Looking for a more sustainable approach to produce amine-based fine chemicals, the use of biomass as feedstocks has appeared as a plausible route due to the vast availability of lignocellulosic materials. ${ }^{6}$ In this respect, the utilization of 5-hydroxymethylfurfural (HFM) or levulinic acid derived from lignocellulosic biomass have arisen as green platform molecules to synthesize aminoalkylfuran derivatives, or lactams skeletons, which are key building blocks in many biologically active natural products. ${ }^{7}$

The use of transition metal nanoparticles as catalysts for a variety of organic transformations has witnessed a dramatic growth in recent times. ${ }^{8}$ Various transition metal nanocatalysts have proven their value in the reductive amination of carbonyl compounds. ${ }^{9}$ Among them, gold nanoparticles (AuNPs) have attracted significant attention due to their unique reactivity, leading to the promotion of reactions under mild conditions. ${ }^{10}$ Traditional methods to synthesize supported AuNPs include co-precipitation, depositionprecipitation, ion-exchange, impregnation and successive reduction and calcinations. ${ }^{11}$ These procedures, however, present some notorious drawbacks, such as the lack of control over nanoparticle size or morphology, and the occurrence of metal leaching from the as-prepared nanoparticles during the catalytic process. Thus, the development of straightforward routes to support gold nanoparticles leading to non-leachable materials presents a remarkable interest. Scaiano and coworkers reported a photochemical synthesis of stable, unprotected AuNPs by using Irgacure 2959 as a photosensitizer. ${ }^{12}$ Later on, the same research group designed a new synthetic route to efficiently prepare AuNPs supported onto nanostructured silica MCM-41 through a one-pot approach where nanoparticles were synthesized and immobilized by using light as a cheap and abundant energy source. The assynthesized materials were successfully used as molecular delivery systems. ${ }^{13}$

Even though the combination of heterogeneous gold nanocatalysts with microreactor technology offers various advantages when compared to batch processes, ${ }^{14}$ research on this topic is scarce. ${ }^{15}$ Besides the inherent process intensification (continuous product formation and catalyst separation) associated to this approach, other advantages include minimized waste production, intrinsically high safety, easy handling of reactants, use of the same catalyst samples for extended periods of time (resulting in high TONs), and the possibility of operating reactions under harsh conditions with simultaneous avoidance of by-product formation. ${ }^{16}$

In this work, we report a highly efficient approach $^{14}$ for the synthesis of gold nanoparticles supported onto mesoporous silica SBA-15 and the catalytic use of this hybrid material for the reductive amination of carbonyl compounds leading to secondary and tertiary amines in batch and flow. Lignocellulosic biomassderived aldehydes can be used for the efficient and green preparation of high added-value aminoalkylfurans and lactams through this process. ${ }^{17}$

\section{Results and discussion}

\section{Preparation of Au@APTES@SBA}

The catalyst was prepared as shown in Scheme 1. Gold nanoparticles (AuNPs) were synthesized and immobilized onto the mesoporous silica by following a one-pot procedure. Firstly, SBA-15 silica was prepared by a conventional sol-gel approach. ${ }^{18}$ This mesoporous solid was refluxed with 3-aminopropyltriethoxysilane in toluene to afford the hybrid amine-based APTES@SBA (2), and the resulting material was added to an aqueous mixture of the gold precursor together with the photosensitizer Irgacure 2959. Then, the yellow solution was placed into a photoreactor and irradiated with 16 mid-range ( $300 \mathrm{~nm}$ ) UV lamps for $30 \mathrm{~min}^{13}$ 


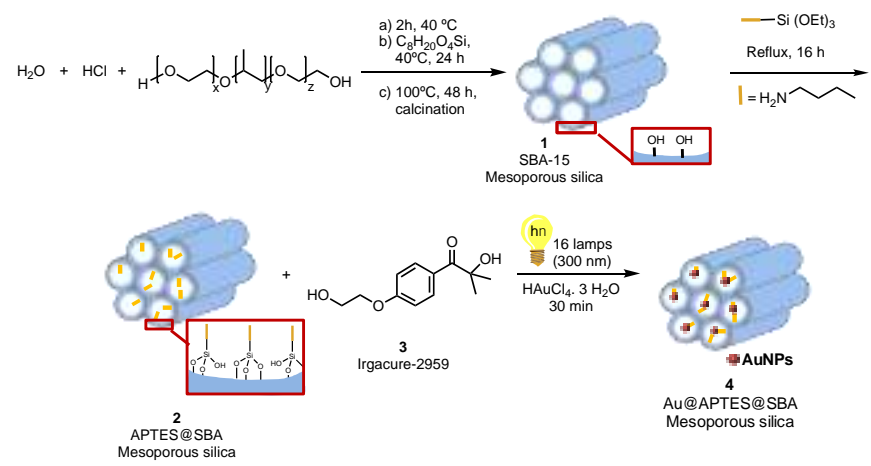

Scheme 1 Schematic illustration of the synthesis of the hybrid catalystAu@APTES@SBA (4).

\section{Characterization of hybrid Au nanoparticles functionalized mesoporous silica}

Firstly, the morphology and structural features of the material were studied by using microscopy techniques (Figure 1). Gold metal is clearly present in the silica as spherical nanoparticles in the size range of 8-15 $\mathrm{nm}$ [Figure 1 (b) and (c); average size of $8.4 \mathrm{~nm}$ ] as shown by TEM. This technique also reveals that the incorporation of AuNPs did not disturb the mesoporous structure of SBA-15, as further confirmed by the X-ray diffraction (XRD) pattern (Figure 2). Indeed, the typical nanochannels of this kind of mesoporous materials are observed in both the pristine SBA-15 silica and in the Au@APTES@SBA synthesized solid [Figure 1 (a) and (c)]. Moreover, mapping spectroscopy revealed the good dispersion of the nanoparticles on the silica matrix [Figure 1 (d)].

Figure 2 shows the low-angle XRD patterns of the mesoporous materials. As it can be observed in the figure, three well-resolved diffraction peaks are present for the three silica types: a very intense peak around $2 \theta=1.2^{\circ}$ and two weak peaks at the $2 \theta$ range between $1.5^{\circ}$ and $2.0^{\circ}$, attributed to the (100), (110) and (200) planes, respectively, ${ }^{19}$ thus demonstrating that there is no alteration in the ordered two-dimensional hexagonal porous structure of the solids during the synthesis of the hybrid catalyst.

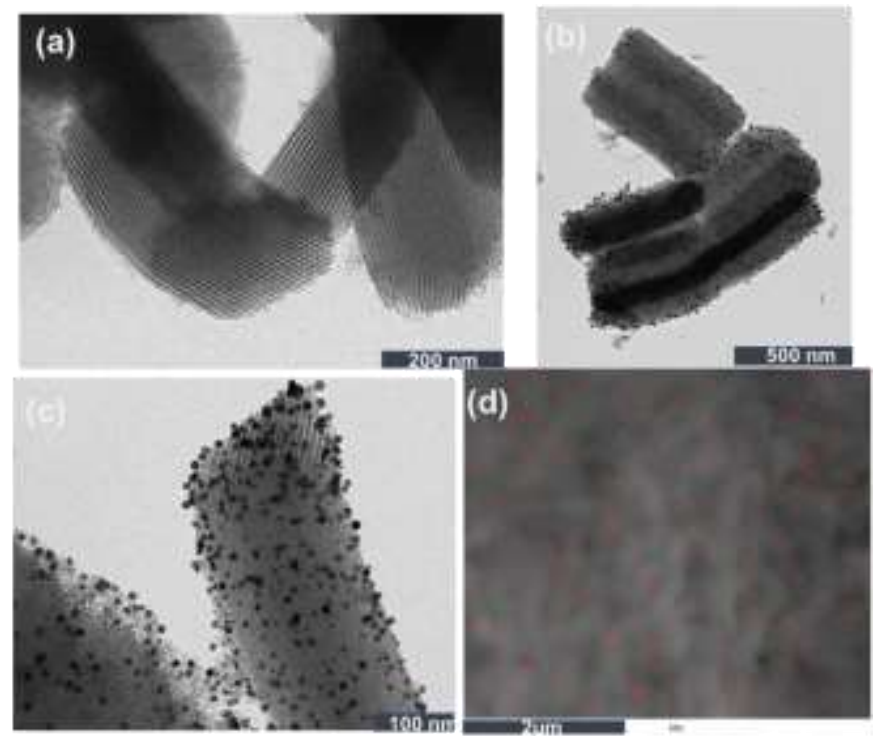

Figure 1 TEM images of the (a) pristine SBA-15 and ( $b$ and $c$ ) Au@APTES@SBA material. (d) TEM elemental mapping of the Au M-edge signals.

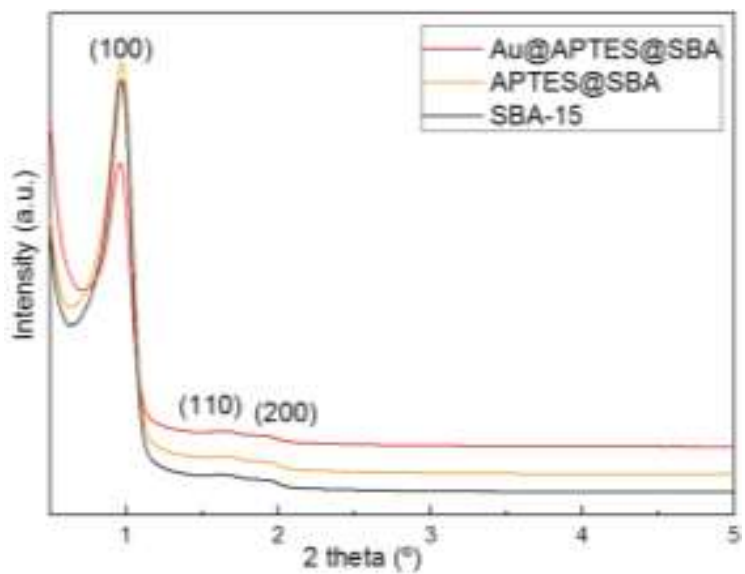

Figure $\mathbf{2}$ Low-angle XRD patterns of the mesoporous silica materials.

The nitrogen adsorption-desorption isotherms and the corresponding pore size distribution of the as-synthesized catalyst are presented in Figure 3. For comparison purposes, the isotherms of the initial SBA-15 and of the APTES@SBA silica are also included. All solids exhibited type IV isotherms with a distinctive nitrogen uptake at the relative pressure of $0.55<P / P_{0}<0.85$, which is characteristic of materials possessing regular cylindrical mesopores with a narrow pore-size distribution. ${ }^{20}$ Based on the isotherms, textural parameters were calculated and listed in Table 1. As expected, both the pore diameter and the surface area decreased after the incorporation of the AuNPs into the mesopores, probably as a result of partial blocking of the porosity in the hybrid material. Besides textural parameters, Table 1 shows the metal loading of the hybrid catalyst $\mathbf{4}$ material as well as the content of the organic moiety (APTES) used to anchor the AuNPs onto the silica matrix (measured as nitrogen \% weight). Notably, all of the gold presumed to be anchored onto the silica material was successfully immobilized, precious waste being completely avoided in this step. 
Table 2 Reductive amination of aldehydes with amines over Au@APTES@SBA hybrid catalyst. ${ }^{a}$

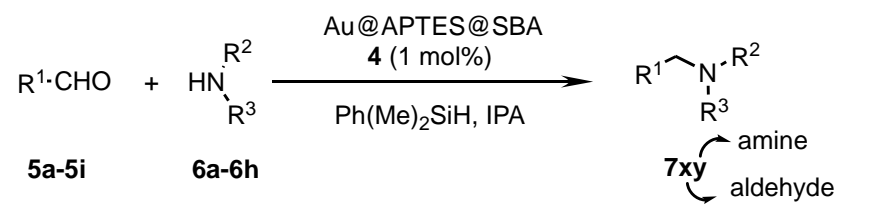

\begin{tabular}{|c|c|c|c|c|}
\hline Aldehyde & $\mathrm{R}^{1}$ & Amine & $\mathrm{R}^{2}$ & $\mathrm{R}^{3}$ \\
\hline $5 a$ & phenyl & $6 \mathbf{a}$ & phenyl & $\mathrm{H}$ \\
\hline $5 b$ & 4-methylphenyl & $6 b$ & 4-methylphenyl & $\mathrm{H}$ \\
\hline $5 c$ & 4-methoxyphenyl & $6 c$ & 4-methoxyphenyl & $\mathrm{H}$ \\
\hline $5 d$ & 4-bromophenyl & $6 d$ & 4-bromophenyl & $\mathrm{H}$ \\
\hline $5 e$ & 3-methylphenyl & $6 e$ & 2,4-dimethoxyphenyl & $\mathrm{H}$ \\
\hline $5 f$ & 3-bromophenyl & $6 f$ & $-\mathrm{CH}_{2} \mathrm{CH}_{2} \mathrm{OCH}_{2} \mathrm{CH}$ & $\mathrm{H}_{2}$ \\
\hline $5 \mathrm{~g}$ & 2-furyl & $6 g$ & butyl & $\mathrm{H}$ \\
\hline $5 \mathrm{~h}$ & 2-naphthyl & $6 \mathrm{~h}$ & $\mathrm{H}$ & $\mathrm{H}$ \\
\hline $5 i$ & 2,2-dimethylvinyl & & & \\
\hline $5 \mathbf{j}$ & hexyl & & & \\
\hline
\end{tabular}

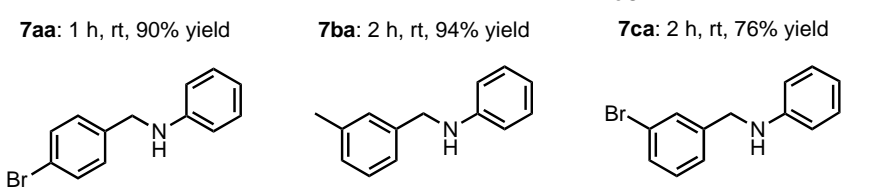

7da: $2 \mathrm{~h}$, rt, $76 \%$ yield

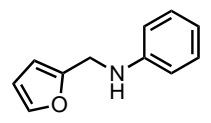

$7 \mathrm{ea}: 2 \mathrm{~h}, \mathrm{rt}, 77 \%$ yield

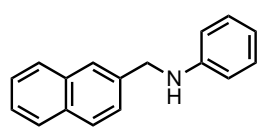

7 fa: $2 \mathrm{~h}, \mathrm{rt}, 77 \%$ yield

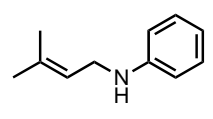

7ga: $2 \mathrm{~h}, \mathrm{rt}, 76 \%$ yield<smiles>CC(C)(C)CNc1ccccc1</smiles>

7ja: $14 \mathrm{~h}, 60^{\circ} \mathrm{C}, 0 \%$ yield<smiles>Brc1ccc(NCc2ccccc2)cc1</smiles>

7ha: $:^{\mathrm{b}, \mathrm{c}} 14 \mathrm{~h}, 60^{\circ} \mathrm{C}, 79 \%$ yield<smiles>Cc1ccc(NCc2ccccc2)cc1</smiles>

7ab: $14 \mathrm{~h}, 60^{\circ} \mathrm{C}, 81 \%$ yield<smiles>COc1ccc(NCc2ccccc2)c(OC)c1</smiles>

7ad: $14 \mathrm{~h}, 60^{\circ} \mathrm{C}, 80 \%$ yield 7 ae: $:^{\mathrm{d}} 24 \mathrm{~h}, 60^{\circ} \mathrm{C}, 61 \%$ yield 7ia: $14 \mathrm{~h}, 60^{\circ} \mathrm{C}, 80 \%$ yield<smiles>COc1ccc(NCc2ccccc2)cc1</smiles>

7ac: $14 \mathrm{~h}, 60^{\circ} \mathrm{C}, 84 \%$ yield

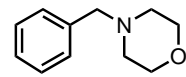

c). ${ }^{24,25}$ To our delight, Au@APTES@SBA provided good yield of 11 $(75 \%)$ within $14 \mathrm{~h}$ at $60{ }^{\circ} \mathrm{C}$, which compares favourably to the heterogeneous catalysts reported so far for such reaction. ${ }^{7,25,26}$ Moreover, and in contrast to other reported supported catalysts, ${ }^{25,27}$ our hybrid material performed the reductive amination of 5-hydroxymethylfurfural under very mild conditions, giving the desired product (13) in $65 \%$ yield within $14 \mathrm{~h}$ at $60{ }^{\circ} \mathrm{C}$.

Encouraged by the catalytic performance and versatility of the Au@APTES@SBA catalyst, we wanted to demonstrate its viability for preparative purposes by scaling-up the preparation of some of the reductive amination products to gram quantities under flow conditions. With this purpose, the two-pump system outlined in Table 3 was assembled. As depicted, a packed bed reactor containing Au@APTES@SBA was fed with two solutions containing, in one case, the selected aldehyde and the corresponding amine and, in the other case, dimethylphenylsilane as the reducing agent. Preliminary evaluation and optimization studies were conducted using a flow microreactor where isopropanol solutions of benzaldehyde and aniline ( $0.41 \mathrm{M}$ each) and dimethylphenylsilane $(0.62 \mathrm{M})$ were simultaneously pumped through a cartridge reactor packed with $0.500 \mathrm{~g}$ of Au@APTES@SBA (0.076 mmol Au) with precise control of the flow rates. The exiting product stream was collected, concentrated under vacuum and analysed by ${ }^{1} \mathrm{H}$ NMR spectroscopy to determine conversion and selectivity. High yields, comparable to those already obtained in the batch reaction were achieved for flow rate $\leq 200 \mu \mathrm{L} \mathrm{min}{ }^{-1}$. Since a further increase in flow rate to $250 \mu \mathrm{L} \mathrm{min}^{-1}$ resulted in lower conversion, a flow rate of $200 \mu \mathrm{L} \mathrm{min}^{-1}$ was selected as the optimal one and used to explore the scope of the reaction in flow.

With the optimized conditions in hand the substrate range was extended to a variety of benzaldehydes previously processed in batch (Table 3). Thus, compounds 7aa-7da, 7ga and 7ab were sequentially prepared using the same flow device loaded with the same sample of Au@APTES@SBA catalyst. Each flow experiment was allowed to run for $2 \mathrm{~h} 30 \mathrm{~min}$ at $200 \mu \mathrm{l} \mathrm{min}{ }^{-1}$ at room temperature (residence time $18 \mathrm{~min}$ ). To avoid crosscontamination, the column was simply rinsed with isopropanol between two consecutive flow experiments. As a general trend, these reductive aminations in flow took place in very high yield (up to $99 \%$ ), clearly improving the corresponding batch processes. The less reactive $p$-toluidine $(6 \mathbf{b})$ required higher temperature $\left(60{ }^{\circ} \mathrm{C}\right.$ ) and longer residence time for full conversion in the reaction with benzaldehyde $\mathbf{5 a}$. Thus, $\mathbf{7 a b}$ was obtained by circulating the corresponding aldehyde and amine through the system for $5 \mathrm{~h} 45$ $\min$ at a combined flow rate of $100 \mu \mathrm{L} \mathrm{min}^{-1}$ and a reaction temperature of $60^{\circ} \mathrm{C}$. Also in this case, the flow process led to higher yield (91\%) than the corresponding one in batch. Overall, six different amines were sequentially prepared in gram amounts, achieving an accumulated TON of 434 in $18 \mathrm{~h}$ of operation. Under these conditions the reductive amination led to yields as high as $99 \%$, which clearly improve those recorded under batch conditions. Remarkably, the employed catalyst cartridge showed no deactivation over the whole period of use. The behavior in isopropyl alcohol sharply contrasts with that observed in methanol. In this last case, the presence of small silica particles in the effluent was visible, and ICP analysis of the catalytic material showed a substancial decrease in the amount of gold present on the catalyst (from $3.02 \%$ to $2.57 \%$ ) after $2.5 \mathrm{~h}$ use in flow for the preparation of 7 aa.

The versatility of the Au@APTES@SBA catalyst could also be demonstrated in the synthesis of isoindolinones, a structural type found in many important biologically active compounds. ${ }^{7 \mathrm{~b}}$ Both electron-donating (OMe and $\mathrm{Me}$ ) and -withdrawing $(\mathrm{Br})$ groups on the aromatic substituents of amines were tolerated, the target isoindolinones 9 a-d being obtained in $80-90 \%$ yields (Scheme $2 a$ ). Finally, the activity of the gold catalyst was tested on the synthesis of high added-value, biomass-derived compounds (in addition to 7ga) from levulinic acid and 5-hydroxymethylfurfural (Scheme 2b- 
Scheme 2 Other reductive amination strategies for the synthesis of value-added products. a)<smiles>O=Cc1ccccc1C(=O)O</smiles>

8

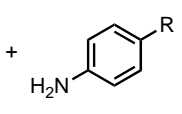

$6 a-6 d$

b)<smiles>CC(=O)CCC(=O)[OH+]</smiles>

10

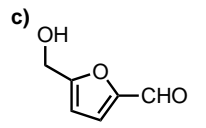

12

$6 a$<smiles>Nc1ccccc1</smiles>

$6 a$

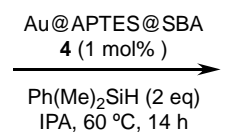

9a, $90 \%$ yield (R: H) 9b, $87 \%$ yield (R: $\mathrm{Me})$ 9c, $90 \%$ yield ( $\mathrm{R}: \mathrm{OMe})$ 9d, $80 \%$ yield ( $\mathrm{R}: \mathrm{Br})$
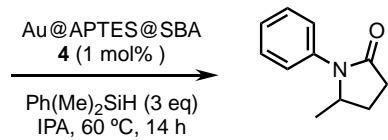

$11,75 \%$
IPA, $60^{\circ} \mathrm{C}, 14 \mathrm{~h}$

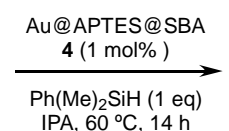

IPA, $60^{\circ} \mathrm{C}, 14 \mathrm{~h}$

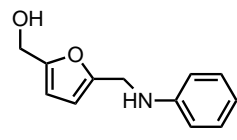

$13,65 \%$
Table 3 Reductive amination of aldehydes over Au@APTES@SBA in continuous flow.

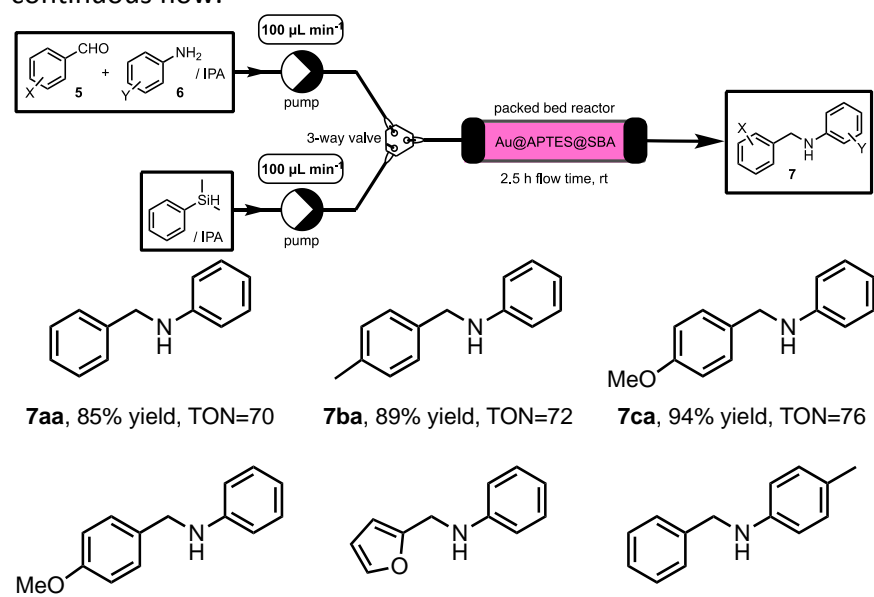

$7 \mathrm{da}, 77 \%$ yield, TON=62 7ga, $99 \%$ yield, $\mathrm{TON}=80 \quad 7 \mathrm{ab},{ }^{\text {a }} 91 \%$ yield, $\mathrm{TON}=74$ ${ }^{a}$ Combined flow rate was $100 \mu \mathrm{L} / \mathrm{min}$. Reactants were circulated for $5.45 \mathrm{~h}$.

\section{Conclusions}

In summary, we have developed a new approach to reductive amination reactions through the use of a Au@APTES@SBA hybrid material and dimethylphenylsilane as the reducing agent. The Au@APTES@SBA catalyst efficiently mediates the reductive amination of a variety of aromatic and $\alpha, \beta$-unsaturated aldehydes with primary (aromatic and aliphatic) and secondary amines under mild conditions. The versatility of the as-synthesized Au@APTES@SBA catalyst has been successfully demonstrated in the preparation of a library of 15 secondary and tertiary amines in isopropanol. Moreover, the new catalyst has also allowed the synthesis of isoindolinone derivatives and the reductive amination of biomass-derived carbonyl compounds (furfural, 5-hydroxymethylfurfural and levulinic acid).

Finally, the suitability of Au@APTES@SBA for the multigram production of a number of amines has been successfully proved. The catalyst is remarkably robust and ideally suited for scale-up and could be operated under continuous flow conditions for ca. $18 \mathrm{~h}$ (TON = 434) with a stable activity-selectivity profile. In this manner, a sequentially operated single catalyst cartridge allowed the reductive amination of odifferent substrates with yields improving those recorded under batch conditions.

\section{Experimental}

Materials. Tetraethyl orthosilicate (TEOS, 98\%) and Pluronic (P-123) were used as silica source and structure-directing agent, respectively. Hydrochloric acid, tetrachloroauric acid $\left(\mathrm{HAuCl}_{4}\right.$. $3 \mathrm{H}_{2} \mathrm{O}$ ), Irgacure-2959, and 3-aminopropyltriethoxysilane (APTES) were also used in the synthetic protocol to obtain the final hybrid mesoporous material. All chemicals were purchased from Aldrich and used as received without further purification.

Preparation of mesoporous SBA-15 silica (SBA). SBA-15 type silica was prepared according to a procedure already described. ${ }^{28} 20.0 \mathrm{~g}$ of pluronic (P123) were dispersed in $150 \mathrm{~mL}$ of water and $600 \mathrm{ml}$ of $2 \mathrm{M} \mathrm{HCl}$ solution. Then, $46.6 \mathrm{~mL}$ of tetraethyl silicate (TEOS) were added to the solution with stirring. This gel mixture was continuously stirred at $40{ }^{\circ} \mathrm{C}$ for $24 \mathrm{~h}$ and finally precipitated in a Teflon-lined autoclave at $100{ }^{\circ} \mathrm{C}$ for $48 \mathrm{~h}$. Finally, the solid was filtered, washed with deionized water, dried in air at room temperature and calcined at $550{ }^{\circ} \mathrm{C}$ under static air conditions for $11 \mathrm{~h}\left(1.86{ }^{\circ} \mathrm{C} \mathrm{min}^{-1}\right)$ in order to remove the surfactant.

Preparation of amino functionalized mesoporous silica, APTES@SBA. Modification of the mesoporous silica material with APTES was done by stirring $5.0 \mathrm{~g}$ of the SBA obtained in the previous step with $2.72 \mathrm{~mL}$ of APTES in toluene at room temperature for $12 \mathrm{~h}$. The white solid APTES@SBA thus obtained was filtered, washed repeatedly with toluene and acetone, and finally dried in air. In a final step the amino functionalized silica was placed into a soxhlet system and was washed with acetone for 15 hours to remove the un-reacted APTES.

Preparation of Gold nanoparticles functionalized mesoporous silica, Au@APTES@SBA. Synthesis and incorporation of AuNPs into the silica network was carried out by using a one-pot strategy based on that proposed by McGilvray and co-workers. ${ }^{29} 0.30 \mathrm{~g}$ of $\mathrm{HAuCl}_{4} \cdot 3 \mathrm{H}_{2} \mathrm{O}$ were added to an aqueous mixture $(230 \mathrm{~mL})$ of the APTES@SBA solid (5.0 g).Then, $0.51 \mathrm{~g}$ of Irgacure-2959 were added and the yellow solution was placed into a photoreactor and irradiated with 16 UVA lamps for $30 \mathrm{~min}$. The final pink solution was then filtered and washed several times with water to remove the non-reacted salt. The air-dried new synthesized hybrid materials were denoted as Au@APTES@SBA (3 wt \% Au attending to ICP analyses). The procedure led to $100 \%$ of incorporation of the gold used during the synthesis of the hybrid material.

General procedure for catalytic reductive amination in batch. Aldehyde $(0.50 \mathrm{mmol})$, amine $(0.50 \mathrm{mmol})$, dimethylphenylsilane (0.75 mmol), isopropanol (1 mL) and the Au@APTES@SBA catalyst (Au: $1.0 \mathrm{~mol} \%$ ) were placed into a $10 \mathrm{~mL}$ vial under a $\mathrm{N}_{2}$ atmosphere. The resulting mixture was vigorously stirred at the corresponding temperature for a given reaction time (see Scheme 2). After completion of the reaction, the supported catalyst was separated by filtration and the reaction mixture was concentrated under vacuum and then purified by flash chromatography (cyclohexane:ethyl acetate) to afford the corresponding product. General procedure for catalytic reductive amination in flow.

The reactor was set up by introducing the Au@APTES@SBA (ca.

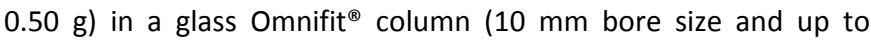
maximal $70 \mathrm{~mm}$ of adjustable bed height). The column was fed with two independent streams, each connected to a syringe pump. Solution A contained a mixture of the selected aldehyde and amine and solution B was prepared with the corresponding amount of phenyldimethyl-silane as reducing agent. Reactions were performed at rt or 60 o $\mathrm{C}$ depending on the optimized conditions 
revealed in batch. In all cases, the collected organic phase was concentrated and the obtained residue was purified by flash column chromatography.

\section{Conflicts of Interest}

There are no conflicts of interest to declare.

\section{Acknowledgements}

This work was funded by the CERCA Programme/Generalitat de Catalunya, and MINECO (grant CTQ2015-69136-R and Severo Ochoa excellence accreditation award 2014-2018 (SEV-2013-0319)). A. I. Carrillo acknowledges the COFUND-Marie Curie action of the European Union's FP7 (291787-ICIQ-IPMP) for a postdoctoral fellowship.

\section{Notes and references}

\footnotetext{
1 J. Mielby, S. Kegnaes and P. Fristup, ChemCatChem, 2012, 4, 1037.

${ }^{2}$ M. Kumar, V. Bhatt, O. S. Nayal, S. Sharma, V. Kumar, M. S. Thakur, N. Kumar, R. Bal, B. Singh and U. Sharma, Catal. Sci. Technol., 2017, 7, 2857.

${ }^{3}$ (a) A. C. Bissember, R. J. Lundgren, S. E. Creutz, J. C. Peters and G. C. Fu, Angew. Chem. Int. Ed., 2013, 52, 5129; (b) A. Wetzel, S.Wockel, M. Schelwies, M. K. Brinks, F. Rominger, P. Hofmann and M. Limbach, Org. Lett., 2013, 15, 266; (c) T. Mizuta, S. Sakaguchi and Y. Ishii, J. Org. Chem., 2005, 70, 2195; (d) B. Klenke and I. H. Gilbert, J. Org. Chem., 2001, 66, 2480; (e) S. Laval, W. Dayoub, A. F. Reguillon, M. Berthod, P. Demonchaux, G. Mignani and M. Lemaire, Tetrahedron Lett., 2009, 50, 7005; (f) A. S. Guram, R. A. Rennels and S. L. Buchwald, Angew. Chem., Int. Ed. Engl., 1995, 34, 348; (g) J. Louie and J. F. Hartwig, Tetrahedron Lett., 1995, 36(21), 3609.
}

${ }^{4}$ (a) J. Won and K. Chung, ACS Catal., 2015, 5, 4846; (b) J. Wu, S. Lu, D. Ge and H. Gu, RSC Adv., 2015, 5, 81395; (c) A. P. Moskovets, D. L. Usanov, O. I. Afanasyev, V. A. Fastovskiy, A. P. Molotkov, K. M. Muratov, G. L. Denisov, S. S. Zlotski, A. F. Smol'yakov, D. A. Loginov and D. Chusov, Org. Biomol. Chem., 2017, 15, 6384; (d) F. Mao, D. Sui, Z. Qi, H. Fan, R. Chen and J. Huang, RSC Adv., 2016, 6, 94068.

${ }^{5}$ (a) S. C. A. Sousa and A. C. Fernandes, Adv. Synth. Catal., 2009, 352, 2218; (b) S. Enthaler, ChemCatChem, 2010, 2, 1411; (c) H. Jaafar, H. Li, L. C. Misal Castro, J. Zheng, T. Roisnel, V. Dorcet, J.- B. Sortais and C. Darcel, Eur. J. Inorg. Chem., 2012, 3546; (d) B. Li, S. Zhang, W. Wu, L. Liang, S. Jiang, L. Chen and Y. Li, RSC Adv., 2017, 7, 31795 .

${ }^{6}$ A. Corma, S. Iborra and A. Veltly, Chem. Rev., 2007, 107, 2411.

7 (a) G. Gao, P. Sun, Y. Li, F. Wang, Z. Zhao, Y. Qin and F. Li, ACS Catal., 2017, 7, 4927; (b) Y. Ogiwara, T. Uchiyama and N. Sakai, Angew. Chem., Int. Ed., 2016, 55, 1864.

${ }^{8}$ For a review, see: Y. Dai, Y. Wang, B. Liu and Y. Yang, Small, 2015, 11, 268.

${ }^{9}$ (a) J. W. Park and Y. K. Chung, ACS Catal., 2015, 5, 4846; (b) R. J. Kalbasi and O. Mazaheri, New J. Chem., 2016, 40, 9627; (c) P. Zhou and Z. Zhang, ChemSusChem, 2017, 10, 1892; (d) S. Enthaler, ChemCatChem, 2010, 2, 1411.

${ }^{10}$ (a) A. Corma and P. Serna, Science, 2006, 313, 332; (b) Y. S. Wagh and N. Asao, J. Org. Chem., 2015, 80, 847; (c) F. -Z. Su, L. He, J. Ni, Y. Cao, H. -Y. He and K. -N. Fan, Chem. Commun., 2008, 3531; (d) E. Vasilikogiannaki, I. Titilas, G. Vassilikogiannakis and M. Stratakis,
Chem. Commun., 2015, 51, 2384; (e) A. Moragues, F. Neatu, V. I. Pârvulescu, M. D. Marcos, P. Amorós and V. Michelet, ACS Catal., 2015, 5, 5060; (f) S. Yudha, I. Kusuma and N. Asao, Tetrahedron, 2015, 71, 6459; (g) B. S. Takale, S. Tao, X. Yu, X. Feng, T. Jin, M. Bao and Y. Yamamoto, Tetrahedron, 2015, 71, 7154; (h) S. Liang, P. Monsen, G. B. Hammond and B. Xu, Org. Chem. Front., 2016, 3, 505; (i) W. Yang, L. Wei, F. Yi and M. Cai, Catal. Sci. Technol., 2016, 6, 4554.

${ }^{11}$ (a) R. Zanella, S. Giorgio, C. R. Henry and C. Louis, J. Phys. Chem. B, 2002, 106, 7634; (b) A. Wolf and F. A. Schüth, Appl. Catal. A, 2002, 226, 1; (c) F. Moreau, G. C. Bond and A. O. Taylor, J. Catal., 2005, 23, 105; (d) W. C. Li, M. Comotti and F. Schüth, J. Catal., 2006, 237, 190; (e) F. Moreau and G. C. Bond, Appl. Catal. A, 2006, 302, 110; (f) S. Al-Sayari, A. F. Carley, S. H. Taylor, G. J. Hutchings, Top. Catal., 2007, 44, 123.

${ }^{12}$ K. L. McGilvray, M. R. Decan, D. Wang and Juan C. Scaiano, J. Am. Chem. Soc., 2006, 128, 15980.

${ }^{13}$ D. T. Marquez, A. I. Carrillo and J. C. Scaiano, Langmuir, 2013, 29, 10521.

${ }^{14}$ F. Schröder, N. Erdmann, T. Noël, R. Luque and E. V. Van der Eycken, Adv. Synth. Catal., 2015, 357, 3141.

${ }^{15}$ (a) A. L. Nuzhdin, E. A. Artiukha, G. A. Bukhtiyarova, S. Yu Zaytsev, P. E. Plyusnin, Y. V. Shubin and V. I. Bukhtiyarov, RSC AdV., 2016, 6, 88366; (b) B. Ballarin, D. Barreca, E. Boanini, M. C. Cassani, P. Dambruoso, A. Massi, A. Mignani, D. Nanni, C. Parise and A. Zaghi, ACS Sustainable Chem. Eng., 2017, 5, 4746.

${ }^{16}$ (a) R. Ricciardi, J. Huskens and W. Verboom, ChemSusChem, 2015, 8, 2586; (b) H. P. L. Gemoets, Y. Su, M. Shang, V. Hessel, R. Luque and T. Noël, Chem. Soc. Rev., 2016, 45, 83; (c) P. Dambruoso, M. Ballestri, C. Ferroni, A. Guerrini, G. Sotgiu, G. Varchi and A. Massi, Green Chem., 2015, 17, 1907.

17 P. T. Anastas, and J. C. Warner, Green Chemistry: Theory and Practice, Oxford University Press: New York, 1998, 30.

${ }_{18}$ D. Zhao, J. Feng, Q. Huo, N. Melosh, G. H. Fredrickson, B. F. Chmelka and G. D. Stucky, Science, 1998, 279, 548.

${ }^{19}$ C. Liu, R. Tan, N. Yu and D. Yin, Micropor. Mesopor. Mater., 2010, 131, 162.

${ }^{20}$ A. Saad, C. Vard, M. Abderrabba and M. M. Chehimi, Langmuir, 2017, 33, 7137.

${ }^{21}$ R. J. Maya, S. Poulose, J. John and R. L. Varma, Adv. Synth. Catal., 2017, 359, 1177.

${ }^{22}$ Y. Ogiwara, W. Shimoda, K. Ide, T. Nakajima and N. Sakai, Eur. J. Org. Chem., 2017, 2866.

${ }^{23}$ R. Kumar, E. Gravel, A. Hagège, H. Li, D. Verma, I. N. N. Namboothiri and E. Doris, ChemCatChem, 2013, 5, 3571.

${ }^{24}$ C. Wu, X. Luo, H. Zhang, X. Liu, G. Ji, Z. Liu and Z. Liu, Green Chem., 2017, 19, 3525.

${ }^{25}$ M.-M. Zhu, L. Tao, Q. Zhang, J. Dong, Y.-M. Liu, H.-Y. He and Y. Cao, Green Chem., 2017, 19, 3880.

26 S. Wang, H. Huang, C. Bruneau and C. Fischmeister, ChemSusChem, 2017, 10, 1.

${ }^{27}$ T. Komanoya, T. Kinemura, Y. Kita, K. Kamata and M. Hara, J. Am. Chem. Soc., 2017, 139, 11493.

${ }^{28}$ A. I. Carrillo, L. C. Schmidt, M. L. Marín, and J. C. Scaiano, Catal. Sci. Technol., 2014, 4, 435. 
${ }^{29}$ K. L. McGilvray, M. R. Decan, D. Wang, and J. C. Scaiano, J. Am. Chem. Soc., 2006, 128, 15980. 